\title{
RNase $\mathbf{R}$ is a highly unstable protein regulated by growth phase and stress
}

\author{
CHENGLU CHEN and MURRAY P. DEUTSCHER \\ Department of Biochemistry and Molecular Biology, Miller School of Medicine, University of Miami, Miami, Florida 33101, USA
}

\begin{abstract}
RNase $\mathbf{R}$ is an important exoribonuclease that participates in the degradation of structured RNAs in Escherichia coli. In earlier work, it was shown that RNase R levels increase dramatically under certain stress conditions, particularly during cold shock and stationary phase. However, the regulatory processes that lead to this elevation are not well understood. We show here that the increase in $\mathbf{R N a s e} R$ in stationary phase is unaffected by the global regulators, $\mathrm{RpoS}$ and (p)ppGpp, and that it occurs despite a major reduction in $r n r$ message. Rather, we find that $R$ Nase $R$ is a highly unstable protein in exponential phase, with a half-life of $\sim 10 \mathrm{~min}$, and that the protein is stabilized in stationary phase, leading to its relative increase. RNase $\mathbf{R}$ is also stabilized during cold shock and by growth in minimal medium, two other conditions that lead to its elevation. These data demonstrate that RNase $R$ is subject to regulation by a novel, posttranslational mechanism that may have important implications for our complete understanding of RNA metabolism.
\end{abstract}

Keywords: exoribonuclease; stationary phase; cold shock; proteolysis

\section{INTRODUCTION}

RNase R, a member of the RNR family of exoribonucleases (Zuo and Deutscher 2001), is a processive $3^{\prime}$-to-5' hydrolytic exoribonuclease active on synthetic polynucleotides, mRNA, rRNA, and tRNA (Cheng and Deutscher 2002). While sharing many structural and catalytic properties with another ribonuclease, RNase II, RNase R is unusual among known Escherichia coli exoribonucleases in that it can digest structured RNAs without the addition of an RNA helicase (Cheng and Deutscher 2002; Vincent and Deutscher 2006, 2009a,b). In vivo, RNase $\mathrm{R}$ plays an important role in degradation of mRNAs with extensive secondary structures (Chen and Deutscher 2005) and in the quality control of rRNA and tRNA (Cheng and Deutscher 2002, 2003; Li et al. 2002; S Chebolu, C Kim, E Quesada, and MP Deutscher, unpubl.). RNase $\mathrm{R}$ is also required for the expression of virulence genes in Shigella and enteroinvasive strains of E. coli (Tobe et al. 1992). It also associates with the tmRNASmpB complex, which releases stalled ribosomes via a process known as trans-translation (Karzai and Sauer 2001;

Reprint requests to: Murray P. Deutscher, Department of Biochemistry and Molecular Biology, Miller School of Medicine, University of Miami, Miami, FL 33101, USA; e-mail: mdeutsch@med.miami.edu; fax: (305) 243-3955.

Article published online ahead of print. Article and publication date are at http://www.rnajournal.org/cgi/doi/10.1261/rna.1981010.
Withey and Friedman 2003). While E. coli cells lacking RNase R grow almost normally under laboratory conditions, cells lacking both polynucleotide phosphorylase (PNPase) and RNase R are inviable (Cheng et al. 1998), indicating some essential, overlapping functions between these two RNases.

RNase $\mathrm{R}$ levels in E. coli increase dramatically under a variety of conditions, including cold shock (Cairrão et al. 2003; Chen and Deutscher 2005), entry into stationary phase, growth in minimal media, and starvation for phosphate, carbon, or nitrogen (Chen and Deutscher 2005). These responses suggest that $\mathrm{RNase} \mathrm{R}$ is a regulated protein that may play an important physiological role under certain stress conditions, and several examples of such a role have been reported. Thus, RNase R complements the cold shock function of CsdA, a DEAD-box helicase, presumably by providing a crucial mRNA decay function at low temperature (Awano et al. 2007). In addition, RNase $\mathrm{R}$ is required for the degradation of ompA mRNA in the stationary phase (Andrade et al. 2006). It is also known that RNase R interacts with the endoribonuclease RNase E and an RNA helicase in the psychrotrophic bacterium Pseudomonas syringae Lz4W (Purusharth et al. 2005), indicating that in this organism RNase $\mathrm{R}$ is preferred over PNPase as a component of the degradosome. Moreover, RNase $\mathrm{R}$ is essential for growth and is required for the maturation of $16 \mathrm{~S}$ and $5 \mathrm{~S}$ rRNA (Purusharth et al. 2007). RNase R also is required for growth 
of Aeromonas hydrophila at low temperatures (Erova et al. 2008).

The regulatory processes that lead to the elevation of RNase R under stress conditions are not understood. It has been suggested that the increase in RNase R protein during cold shock is a consequence of a quantitatively similar increase in the amount of $r n r$ message, due to the latter's enhanced stability (Cairrão et al. 2003). However, given the much lower level of translation at low temperature, it is not clear how this could account for the increase of RNase $\mathrm{R}$ protein at $10^{\circ} \mathrm{C}$ compared with $37^{\circ} \mathrm{C}$. It is also not known whether the up-regulation of RNase $\mathrm{R}$ in the stationary phase might be due to stabilization of $r n r$ mRNA. In fact, we show here that the $r n r$ message actually decreases in the stationary phase, so that the elevation of RNase R cannot be due to stabilization of its message. Rather, we find that RNase $\mathrm{R}$ is an extremely unstable protein in the exponential phase that becomes stabilized during the stationary phase and other stress conditions, and that it is this stabilization that leads to its increased levels when compared with the exponential phase at $37^{\circ} \mathrm{C}$.

\section{RESULTS AND DISCUSSION}

In addition to cold shock (Cairrão et al. 2003; Chen and Deutscher 2005), various other slow growth or no growth conditions were observed to lead to the elevation of RNase $\mathrm{R}$ specific activity and RNase $\mathrm{R}$ protein compared with that found in cells growing exponentially in rich media (Chen and Deutscher 2005; Andrade et al. 2006). These conditions include growth in minimal media, starvation for certain nutrients, and the stationary phase. Our tentative assumption was that the same regulatory process (or processes) underlies the increase in RNase R in all of these situations; consequently, for these studies, we focused primarily on the stationary phase, since much information is already available about metabolic regulation upon entry of cells into this stage of growth (Hengge-Aronis 1996; Nyström 2004).

\section{Effect of RpoS and (p)ppGpp}

We turned our attention initially to RpoS and (p)ppGpp, two global regulators known to play an important role during the stationary phase and/or slow growth conditions. First, an $\mathrm{rpoS}^{-}$null allele was introduced into strain CAN20-12E, and the resulting strain was examined to determine whether RNase $\mathrm{R}$ levels still increase in the stationary phase when RpoS is absent. In three separate experiments, there was no difference in the increase in RNase R specific activity between the RpoS ${ }^{-}$strain and its $\mathrm{RpoS}^{+}$parent (data not shown). The same conclusions were drawn from experiments in a $\mathrm{MG} 655 \mathrm{I}^{-} \mathrm{II}^{-}$background.

In a second set of experiments, strain CF1363 (MG1655 $r e l A^{-} \operatorname{spoT}^{-}$), constructed by Dr. Michael Cashel (National
Institutes of Health), and unable to synthesize (p)ppGpp, was examined. In two separate experiments, the increase in RNase $\mathrm{R}$ protein in the stationary phase, determined by Western blotting and densitometry, was unaffected by the absence of (p)ppGpp (data not shown). Inasmuch as RNase II is present at normal levels in this strain, it was not possible to measure RNase $\mathrm{R}$ by its enzymatic activity. Nevertheless, these data suggest that neither RpoS nor (p)ppGpp are required for the elevation of RNase $\mathrm{R}$ in the stationary phase.

\section{rnr mRNA in cold shock and the stationary phase}

In earlier work by Cairrão et al. (2003), it was shown that the increase in RNase $\mathrm{R}$ protein upon cold shock is concomitant with an increase in the amount of $r n r$ message. As shown in Figure 1A, we have confirmed those results using dot-blot analysis. Thus, at $10^{\circ} \mathrm{C}$ the total amount of $r n r$ message increased about fivefold over a period of $60 \mathrm{~min}$. However, in contrast to the cold shock data, when the same analysis was used for comparison of the $r n r$ message in the exponential and stationary phases in three separate experiments, it was found that the mRNA actually decreased $\sim 85 \%$ in the stationary phase (Fig. 1B). A reduction in the amount of $r n r$ transcript in the stationary phase was also suggested by the work of Cairrão and Arraiano (2006) and by microarray analysis (Sangurdekar et al. 2006). Based on this information, it is clear that the increase in RNase $\mathrm{R}$ protein and its activity in the stationary phase cannot be due to elevation of $r n r$ mRNA. These data suggest that the regulatory processes that lead to the elevation of RNase $\mathrm{R}$ during cold shock and the stationary phase may be different.

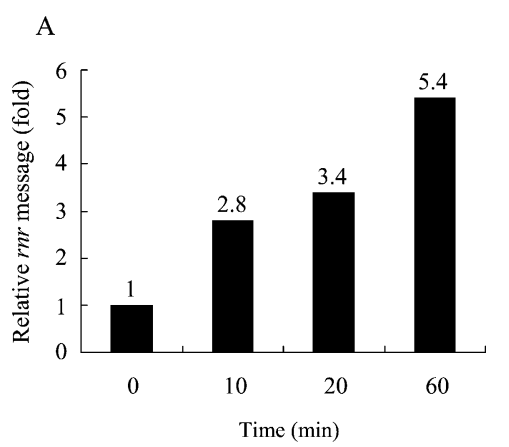

B

FIGURE 1. Level of $r n r$ message during cold shock and the stationary phase. Total RNA was extracted from CAN20-12E cells using the RNeasy extraction kit (Qiagen), and was quantitated by absorbance at $260 \mathrm{~nm}$. The amount of $r n r$ message was determined using dot blots (see Materials and Methods). (A) RNA from cells before and up to 60 min after cold shock at $10^{\circ} \mathrm{C}$. The amount of $r n r$ message prior to transfer to $10^{\circ} \mathrm{C}$ was set at 1 . (B) Exponential phase cells (exp) were extracted when the culture reached an $A_{550}$ of 0.3 . Stationary phase cells (stat) were grown overnight. The data are the average of three experiments, which agreed almost exactly; the amount of $r n r$ mRNA in the exponential phase has been set at 1 . 
RNase $R$ is an unstable protein in the exponential phase

In view of the findings that the transcriptional regulators, RpoS and (p)ppGpp, had no effect on RNase R elevation, and that the $r n r$ message decreased in the stationary phase even though the RNase $\mathrm{R}$ protein increased, it appeared likely that transcriptional regulation and mRNA stability were not involved. Also, since the amount of $r n r$ mRNA was greatly reduced in the stationary phase, it seemed unlikely that increased synthesis of the RNase R protein was the explanation for its elevation. Consequently, we focused our attention on the protein itself, and on its stability.

To examine the stability of RNase R, CAN20-12E cells growing in the exponential phase were treated with chloramphenicol to inhibit new protein synthesis, and the amount of preexisting RNase $\mathrm{R}$ was determined by immunoblotting. The Western blot in Figure 2A shows that RNase R was extremely unstable in exponential phase cells, corresponding to a half-life of $\sim 10 \mathrm{~min}$ (Fig. 2B). Identical results were obtained in the MG1655 $\mathrm{I}^{-} \mathrm{II}^{-}$strain. This unexpected finding was confirmed by measurement of RNase R activity (Fig. 2C). As can be seen, RNase R specific activity also decreased after chloramphenicol treatment at essentially the same rate as RNase R protein, as would be expected if the active protein were removed. These data strongly support the conclusion that RNase R undergoes a rapid turnover. In contrast, a similar experi-
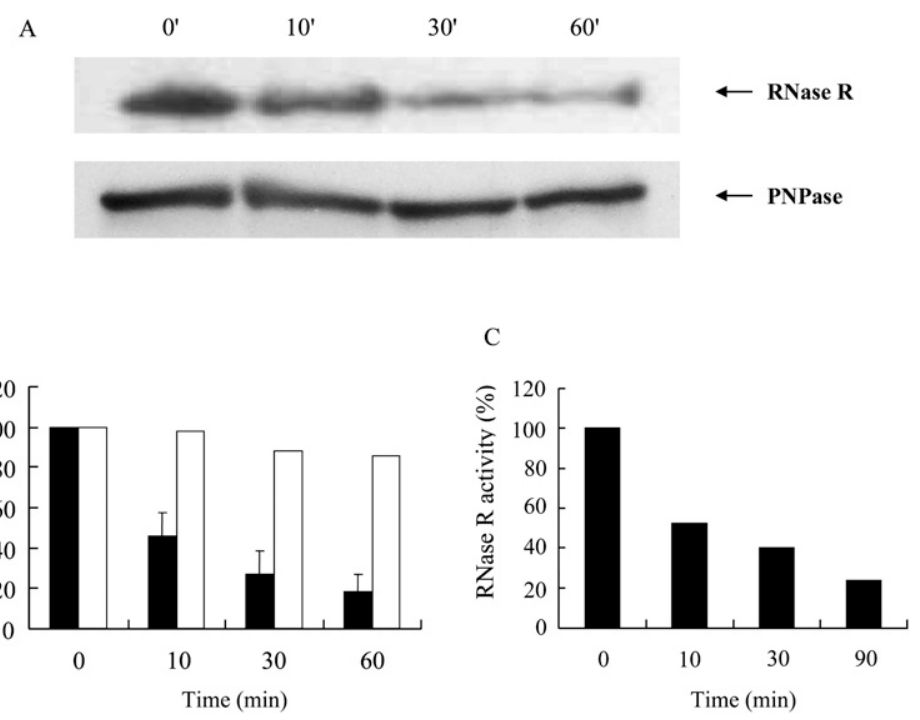

FIGURE 2. Stability of RNase R in the exponential phase. CAN20-12E cells were grown in YT medium, treated with chloramphenicol, and assayed for RNase R protein and activity (see Materials and Methods). (A) Representative blot of samples for RNase R and PNPase before and up to $60 \mathrm{~min}$ after addition of chloramphenicol. (B) Quantitation of four experiments, as shown in $A$, for RNase $\mathrm{R}$ and one experiment for PNPase. (Black bars) RNase $\mathrm{R}$, (white bars) PNPase. (C) RNase $\mathrm{R}$ activity for a representative experiment up to $90 \mathrm{~min}$ after chloramphenicol addition. RNase $\mathrm{R}$ protein and activity at zero time of chloramphenicol addition were set at $100 \%$. ment with PNPase showed that it is stable in the exponential phase (Fig. 2A).

\section{RNase $\mathbf{R}$ is stable in the stationary phase}

In contrast to the instability of RNase $\mathrm{R}$ in the exponential phase, both the protein and enzyme activity remained stable after chloramphenicol treatment of stationary phase cells. Thus, as shown in Figure 3A, there was no change in the amount of RNase $\mathrm{R}$ protein for at least $4 \mathrm{~h}$ after chloramphenicol addition. RNase $\mathrm{R}$ was also stabilized in stationary phase MG1655 $\mathrm{I}^{-} \mathrm{II}^{-}$. Likewise, the specific activity of RNase R remained essentially constant for $4.5 \mathrm{~h}$ after treatment (Fig. 3C). These data indicate that the stability of RNase R in the stationary phase differs dramatically from that of the exponential phase enzyme. Moreover, these observations likely provide an explanation for the increased amount of RNase R in cells in the stationary phase compared with those growing exponentially (see below).

\section{RNase $\mathbf{R}$ is stable in minimal medium}

In earlier work, we showed that RNase R also is elevated in cells growing in M9 minimal medium compared with those growing in rich medium (Chen and Deutscher 2005). To determine whether this increase in RNase $\mathrm{R}$ also can be attributed to enhanced stability of the protein, cells growing exponentially in M9 medium were treated with chloramphenicol, as before, and the fate of RNase $\mathrm{R}$ was examined. Under these conditions, the amount of RNase $\mathrm{R}$ protein was unchanged for at least $60 \mathrm{~min}$ (data not shown), revealing another situation in which RNase $\mathrm{R}$ is stabilized. Thus, taken together with the stabilization of RNase R in the stationary phase, these data suggest that slower cell growth rates may lead to a reduction in RNase $\mathrm{R}$ turnover.

\section{RNase $\mathbf{R}$ is stable during cold shock}

As a further test of the relationship between slow growth and stabilization of RNase R, we examined RNase R under cold shock conditions after addition of chloramphenicol. The data in Figure 4 show first, in confirmation of earlier results, that the level of RNase R was greatly elevated in cells grown at $10^{\circ} \mathrm{C}$ compared with $37^{\circ} \mathrm{C}$. Second, the Western analysis showed that the increased amount of RNase $\mathrm{R}$ was stable for many hours after chloramphenicol 
A

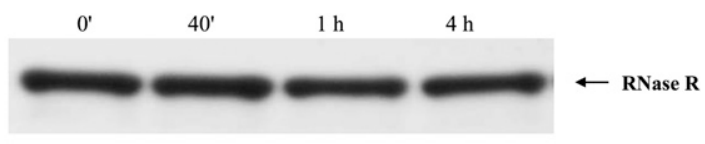

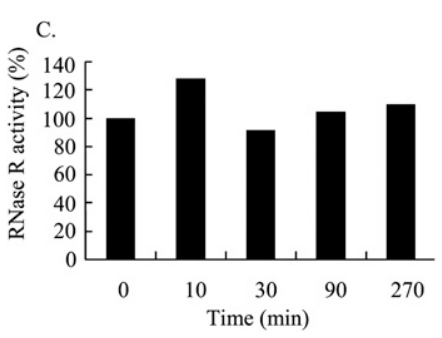

FIGURE 3. Stability of RNase R in the stationary phase. CAN20-12E cells were grown overnight in YT medium, treated with chloramphenicol, and assayed for RNase R protein and activity (see Materials and Methods). (A) Representative Western blot of samples before and up to $4 \mathrm{~h}$ after addition of chloramphenicol. (B) Quantitation of three experiments as shown in $A$. (C) RNase R activity for a representative experiment up to $270 \mathrm{~min}$ after chloramphenicol addition. RNase $\mathrm{R}$ protein and activity at zero time of chloramphenicol addition were set at $100 \%$.

addition. Thus, as with other slow growth conditions, growth of E. coli at $10^{\circ} \mathrm{C}$ leads to stabilization of RNase R.

\section{Effect of proteases on RNase R stability}

The most direct explanation for the rapid turnover of RNase R in rapidly growing cells is proteolytic degradation. To test this possibility, we carried out preliminary experiments to determine the level of RNase $\mathrm{R}$ in various protease-deficient mutant cells with the expectation that cells lacking the protease that acted on RNase $\mathrm{R}$ would contain increased levels of nuclease activity in exponential phase cells. The null mutants screened for RNase R activity included those lacking Lon, ClpXP, and HslUV proteases. For the $\operatorname{clp} P, \operatorname{clp} X$, and $h s l V$ mutant strains examined, we observed a slight elevation of RNase R activity in exponential phase cells (about twofold). On the other hand, in cells lacking Lon protease, RNase R activity was elevated more than threefold (data not shown). These data suggested that Lon protease might be a major contributor to RNase $\mathrm{R}$ turnover.

To examine this point in more detail, the stability of RNase $\mathrm{R}$ was examined in the lon mutant strain. In this strain, the half-life of RNase $\mathrm{R}$ in the exponential phase was $\sim 90$ min compared with the $\sim 10$-min half-life in cells containing Lon (Fig. 2), supporting the idea that this protease may be involved in RNase R turnover. However, we cannot completely eliminate the possibility that this apparent role for Lon is a consequence of slower growth of the mutant strain. All of the protease mutant strains examined grew more slowly than the protease ${ }^{+}$parent; the Lon ${ }^{-}$strain grew more rapidly than the other proteasedeficient mutants, but it still was slower than the parent (67 min versus $30 \mathrm{~min}$ ). Thus, further work will be needed to confirm that the role of Lon is due to its direct action on RNase R, rather than to a more complicated indirect effect, as well as to determine whether any other proteases also might be involved.

The data presented indicate that RNase $\mathrm{R}$ is an extremely unstable protein in cells growing exponentially, with a halflife of $\sim 10 \mathrm{~min}$. Although a number of other unstable bacterial proteins have been identified, most proteins are stable during the exponential phase (Gottesman 2003; Jenal and Hengge-Aronis 2003; Ehrmann and Clausen 2004), and this high degree of instability of RNase R has not been observed previously for RNases. Interestingly, the related protein RNase II also is somewhat unstable (half-life $\sim 50 \mathrm{~min}$ ), and its instability is affected by the gene gmr (Cairrão et al. 2001). Our data also show that RNase R becomes stabilized under a variety of physiological conditions that lead to slower growth. These findings confirm that RNase $\mathrm{R}$ is regulated under different growth conditions, and show that protein stability plays a role in this regulation.

Taken together, this information supports the conclusion that the increase in RNase R observed in the stationary phase is simply a consequence of its enhanced stabilization relative to the exponential phase. This conclusion is strengthened by the fact that the elevation of RNase $\mathrm{R}$ occurs even though the amount of $r n r$ message is actually reduced under these conditions. The data also raise the possibility that a major contributor to the elevation of RNase R observed during cold shock (Cairrão et al. 2003; Chen and Deutscher 2005) might be protein stabilization rather than being solely due to increased $r n r$ mRNA, as concluded by Cairrão et al. (2003). Inasmuch as protein synthesis under cold shock conditions at $10^{\circ} \mathrm{C}$ is greatly

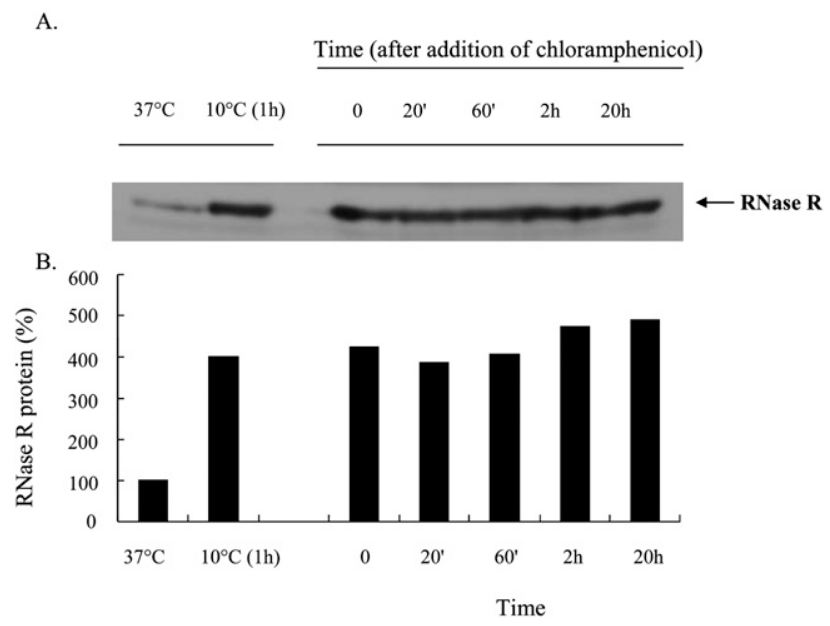

FIGURE 4. Stability of RNase R during cold shock. CAN20-12E cells were grown to an $\mathrm{A}_{550}$ of $\sim 0.3$ and transferred to $10^{\circ} \mathrm{C}$. After $1 \mathrm{~h}$ at this temperature, one portion was withdrawn for analysis and a second portion was subjected to chloramphenicol treatment as in Figure 2. (A) Western blot of RNase R at $37^{\circ} \mathrm{C}$, after $1 \mathrm{~h}$ at $10^{\circ} \mathrm{C}$, and up to $20 \mathrm{~h}$ after chloramphenicol addition. (B) Quantitation of data in $A$. The amount of RNase $\mathrm{R}$ protein at $37^{\circ} \mathrm{C}$ was set to $100 \%$. 
reduced relative to $37^{\circ} \mathrm{C}$, the increase in the $r n r$ message at the lower temperature may serve only to maintain RNase R synthesis at a level comparable to what it was at $37^{\circ} \mathrm{C}$, whereas it is the additional stabilization of the RNase $\mathrm{R}$ protein during cold shock that is responsible for its dramatic elevation compared with $37^{\circ} \mathrm{C}$. A more-detailed examination of RNase R synthesis and protein synthesis under cold shock conditions will be needed to confirm this idea.

Of most interest for future studies is the understanding of the reasons for the differential stability of exponential and stationary phase RNase R's. Several possibilities can be envisaged: Most simply, RNase R may be intrinsically sensitive to proteolytic degradation, and some change in its structure (e.g., covalent modification or association with another protein) may stabilize it in the stationary phase. Alternatively, an adaptor protein may associate with RNase $\mathrm{R}$ only in the exponential phase and sensitize it to the action of a protease. Such a mechanism has been found to render RpoS unstable in exponential phase cells (Gottesman 1999, 2003; Jenal and Hengge-Aronis 2003). In fact, in this system, regulation of RpoS turnover can be extremely complicated, encompassing an anti-adaptor protein and effectors that influence the amount of the anti-adaptor (Bougdour and Gottesman 2007). Other examples of regulation by proteolysis also have been reviewed (Jenal and Hengge-Aronis 2003). Exactly which process operates for RNase $\mathrm{R}$ and which proteases are involved still remain to be determined. Nevertheless, the studies presented here indicate that an important component of the RNA degradative machinery in $E$. coli is subject to regulation by a previously unrecognized mechanism that may have important implications for our complete understanding of RNA metabolism.

\section{MATERIALS AND METHODS}

\section{Materials}

$\left[{ }^{3} \mathrm{H}\right] \operatorname{poly}(\mathrm{A})$ and poly(A) were obtained from Amersham Pharmacia Biotech and Sigma Chemical, respectively. $\left[\gamma^{32} \mathrm{P}\right]$ ATP $(6000 \mathrm{Ci} / \mathrm{mmol})$ was purchased from PerkinElmer Life Sciences. The antibody against RNase $\mathrm{R}$ was prepared from purified protein (Cheng and Deutscher 2002) by Sigma-Genosys. The RNase R antibody was purified by Dr. W. Liang (University of Miami) using standard procedures (Lin et al. 1996). The antibody against PNPase was a gift from Dr. C. Jain (University of Miami). Antirabbit IgG HRP conjugate was from Santa Cruz Biotechnology. DNA oligomers were synthesized by Sigma Chemical. All other chemicals were reagent grade.

\section{Bacterial strains and growth conditions}

The E. coli $\mathrm{K} 12$ strain CAN20-12E (RNase $\mathrm{I}^{-} \mathrm{II}^{-} \mathrm{D}^{-} \mathrm{BN}^{-}$) and its derivative CAN20-12E $\mathrm{R}^{-}$(RNase $\mathrm{I}^{-} \mathrm{II}^{-} \mathrm{D}^{-} \mathrm{BN}^{-} \mathrm{R}^{-}$) have been described previpusly (Cheng et al. 1998). MG1655 I- $\mathrm{II}^{-}$and its derivative MG1655 $\mathrm{I}^{-} \mathrm{II}^{-} \mathrm{R}^{-}$were obtained from Dr. Michael Zundel (University of Miami) (Zundel et al. 2009). Various mutant alleles from the Keio collection, a kind gift from Dr. Kenneth Rudd (University of Miami) (Baba et al. 2006), were introduced into strain MG1655 $\mathrm{I}^{-} \mathrm{II}^{-}$by phage P1-mediated transduction using P1vir.

Cells were grown in liquid culture in YT medium or M9 minimal medium supplemented with $2 \%$ glucose. Antibiotics, when present, were at the following concentrations: kanamycin, $25 \mu \mathrm{g} / \mathrm{mL}$; tetracycline, $12.5 \mu \mathrm{g} / \mathrm{mL}$. Normally, cells were grown at $37^{\circ} \mathrm{C}$ and were monitored by absorbance measurements at 550 $\mathrm{nm}$. Exponential phase cells were collected at $\sim 0.3 \mathrm{~A}_{550}$. Stationary phase cells were collected after overnight growth. For cold shock experiments, exponential phase cells were first grown in YT medium at $37^{\circ} \mathrm{C}$ prior to shifting to the experimental condition. Details are presented in the Figure 4 legend.

\section{Preparation of cell extracts}

Cell extracts for RNase $\mathrm{R}$ assays were prepared by sonication as previously described (Chen and Deutscher 2005). Cell extracts for immunoblotting were prepared by boiling cells for $5 \mathrm{~min}$ in a cell lysis buffer containing $50 \mathrm{mM}$ Tris- $\mathrm{Cl}$ at $\mathrm{pH} 7.5$ and $1 \%$ sodium dodecyl sulfate.

\section{Assay of RNase R}

The activity of RNase R was determined using an acid soluble assay as previously described (Deutscher et al. 1984). Assays were carried out in $50-\mu \mathrm{L}$ reaction mixtures containing $20 \mathrm{mM}$ Tris- $\mathrm{Cl}$ at $\mathrm{pH} 8.0,0.25 \mathrm{mM} \mathrm{MgCl}, 300 \mathrm{mM} \mathrm{KCl}, 40 \mu \mathrm{g}\left[{ }^{3} \mathrm{H}\right]$ poly(A) (50$100 \mathrm{cpm} / \mathrm{nmol})$, and $30 \mu \mathrm{L}$ of the indicated cell extract. Reaction mixtures were incubated for $30 \mathrm{~min}$ at $37^{\circ} \mathrm{C}$.

\section{Immunoblotting of RNase R}

To determine the amount of RNase R protein, cell extracts were resolved by $8 \%$ SDS-PAGE and subjected to immunoblotting with purified RNase R antibody (Chen and Deutscher 2005). Underexposed films were used for quantitation by Quantity One (Bio$\mathrm{Rad})$.

\section{Measurement of $r n r$ mRNA}

The rnr message was quantitated using dot blots following the procedure in the Bio-Rad instruction manual for alkaline denaturation and fixation of RNA. Hybridization was carried out according to the standard protocol in the GeneScreen Plus manual (PerkinElmer Life Sciences) using a 96-well dot-blot apparatus (Bio-Rad Laboratories). Samples of 1-15 $\mu \mathrm{g}$ of total RNA preparations were used. Membranes were allowed to air dry and were then subjected to hybridization at $50^{\circ} \mathrm{C}$ with a ${ }^{32} \mathrm{P}$-labeled DNA probe (TCAGCTTCGCGTTCCTGGAA). Membranes were then washed five times at $55^{\circ} \mathrm{C}$. Membrane-bound radioactivity was visualized using a PhosphorImager. Quantification was carried out with ImageJ (Abramoff et al. 2004)

\section{Measurement of protein stability}

Cells were grown under normal conditions to an $A_{550}$ of $\sim 0.3$. A portion of cells was collected for the zero time point; chloramphenicol was added to the remaining culture at $200 \mu \mathrm{g} / \mathrm{mL}$ to 
completely inhibit new protein synthesis. Cells were collected at the indicated times, lysed, and assayed by a Western blot to determine the amount of RNase $\mathrm{R}$ present.

\section{ACKNOWLEDGMENTS}

We thank Drs. Chaitanya Jain and Arun Malhotra and members of the laboratory for helpful discussions and comments. This work was supported by Grant GM16317 from the National Institutes of Health.

Received October 30, 2009; accepted January 12, 2010.

\section{REFERENCES}

Abramoff MD, Magelhaes PJ, Ram SJ. 2004. Image processing with ImageJ. Biophotonics Int 11: 36-42.

Andrade JM, Cairrão F, Arraiano CM. 2006. RNase R affects gene expression in stationary phase: Regulation of ompA. Mol Microbiol 60: 219-228.

Awano N, Xu C, Ke H, Inoue K, Inouye M, Phadtare S. 2007. Complementation analysis of the cold-sensitive phenotype of the Escherichia coli csdA deletion strain. J Bacteriol 189: 5808-5815.

Baba T, Ara T, Hasegawa M, Takai Y, Okumura Y, Baba M, Datsenko KA, Tomita M, Wanner BL, Mori H. 2006. Construction of Escherichia coli K-12 in-frame, single-gene knockout mutants: The Keio collection. Mol Syst Biol 2: 2006.0008.

Bougdour A, Gottesman S. 2007. ppGpp regulation of RpoS degradation via anti-adaptor protein IraPT. Proc Natl Acad Sci 104: 12896-12901.

Cairrão F, Arraiano CM. 2006. The role of endoribonucleases in the regulation of RNase R. Biochem Biophys Res Commun 343: 731737.

Cairrão F, Chora A, Zhilhão R, Carpoussis AJ, Arraiano CM. 2001. RNase II levels change according to the growth conditions: Characterization of gmr, a new Escherichia coli gene involved in the modulation of RNase II. RNA 39: 1550-1561.

Cairrão F, Cruz A, Mori H, Arraiano CM. 2003. Cold shock induction of RNase R and its role in the maturation of the quality control mediator SsrA/tmRNA. Mol Microbiol 50: 1349-1360.

Chen C, Deutscher MP. 2005. Elevation of RNase R in response to multiple stress conditions. J Biol Chem 280: 34393-34396.

Cheng Z-F, Deutscher MP. 2002. Purification and characterization of the Escherichia coli exoribonuclease RNase R. J Biol Chem 277: 21624-21629.

Cheng Z-F, Deutscher MP. 2003. Quality control of ribosomal RNA mediated by polynucleotide phosphorylase and RNase R. Proc Natl Acad Sci 100: 6388-6393.

Cheng Z-F, Zuo Y, Li Z, Rudd KE, Deutscher MP. 1998. The vacB gene required for virulence in Shigella flexneri and Escherichia coli encodes the exoribonuclease RNase R. J Biol Chem 273: 1407714080.

Deutscher MP, Marlor CW, Zaniewski R. 1984. Ribonuclease T: New exoribonuclease possibly involved in end-turnover of tRNA. Proc Natl Acad Sci 81: 4290-4293.
Ehrmann M, Clausen T. 2004. Proteolysis as a regulatory mechanism. Annu Rev Genet 38: 709-724.

Erova TE, Kosykh VG, Fadl AA, Sha J, Horneman AJ, Chopra AK. 2008. Cold shock exoribonuclease $\mathrm{R}$ (VacB) is involved in Aeromonas hydrophila pathogenesis. J Bacteriol 190: 3467-3474.

Gottesman S. 1999. Regulation by proteolysis: Developmental switches. Curr Opin Microbiol 2: 142-147.

Gottesman S. 2003. Proteolysis in bacterial regulatory circuits. Annu Rev Cell Dev Biol 19: 565-587.

Hengge-Aronis R. 1996. Back to log phase: $\sigma \mathrm{S}$ as a global regulator in the osmotic control of gene expression in Escherichia coli. Mol Microbiol 21: 887-893.

Jenal U, Hengge-Aronis R. 2003. Regulation by proteolysis in bacterial cells. Curr Opin Microbiol 6: 163-172.

Karzai AW, Sauer RT. 2001. Protein factors associated with the SsrA:SmpB tagging and ribosome rescue complex. Proc Natl Acad Sci 98: 3040-3044.

Li Z, Reimers S, Pandit S, Deutscher MP. 2002. RNA quality control: Degradation of defective transfer RNA. EMBO J 21: 1132-1138.

Lin C, Ahmad M, Cashmore AR. 1996. Arabidopsis cryptochrome 1 is a soluble protein mediating blue light-dependent regulation of plant growth and development. Plant J 10: 893-902.

Nyström T. 2004. Stationary-phase physiology. Annu Rev Microbiol 58: $161-181$.

Purusharth RI, Klein F, Sulthana S, Jäger S, Jagannadham MV, Evguenieva-Hackenberg E, Ray MK, Klug G. 2005. Exoribonuclease $\mathrm{R}$ interacts with endoribonuclease $\mathrm{E}$ and an RNA-helicase in the psychrotrophic bacterium Pseudomonas syringae Lz4W. J Biol Chem 280: 14572-14578.

Purusharth RI, Madhuri B, Ray MK. 2007. Exoribonuclease R in Pseudomonas syringae is essential for growth at low temperature and plays a novel role in the $3^{\prime}$ end processing of 16 and $5 \mathrm{~S}$ ribosomal RNA. J Biol Chem 282: 16267-16277.

Sangurdekar DP, Srienc F, Khodursky AB. 2006. A classification based framework for quantitative description of large-scale microarray data. Genome Biol 7: R32. doi: 10.1186/gb-2006-7-4-r32.

Tobe T, Sasakawa C, Okada N, Honma Y, Yoshikawa M. 1992. vacB, a novel chromosomal gene required for expression of virulence genes on the large plasmid of Shigella flexneri. J Bacteriol 174: 6359-6367.

Vincent HA, Deutscher MP. 2006. Substrate recognition and catalysis by the exoribonuclease RNase R. J Biol Chem 281: 29769-29775.

Vincent HA, Deutscher MP. 2009a. The roles of individual domains of RNase $\mathrm{R}$ in substrate binding and exoribonuclease activity. The nuclease domain is sufficient for digestion of structured RNA. J Biol Chem 284: 486-494.

Vincent HA, Deutscher MP. 2009b. Insights into how RNase R degrades structured RNA: Analysis of the nuclease domain. $J \mathrm{Mol}$ Biol 387: 570-583.

Withey JH, Friedman DI. 2003. A salvage pathway for protein structures: tmRNA and trans-translation. Annu Rev Microbiol 57: 101-123.

Zundel MA, Basturea GN, Deutscher MP. 2009. Initiation of ribosome degradation during starvation in Escherichia coli. RNA 15: 977-983.

Zuo Y, Deutscher MP. 2001. Exoribonuclease superfamilies: Structural analysis and phylogenetic distribution. Nucleic Acids Res 29: $1017-1026$. 

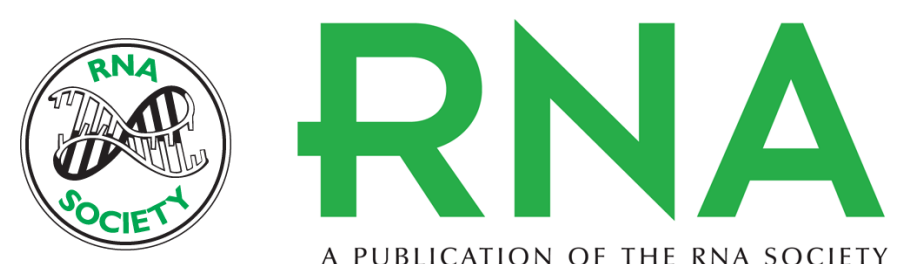

A PUBLICATION OF THE RNA SOCIETY

\section{RNase $R$ is a highly unstable protein regulated by growth phase and stress}

Chenglu Chen and Murray P. Deutscher

RNA 2010 16: 667-672 originally published online February 25, 2010

Access the most recent version at doi:10.1261/rna.1981010

$\begin{array}{ll}\text { References } & \begin{array}{l}\text { This article cites } 33 \text { articles, } 17 \text { of which can be accessed free at: } \\ \text { http://rnajournal.cshlp.org/content/16/4/667.full.html\#ref-list-1 }\end{array}\end{array}$

License

Email Alerting Receive free email alerts when new articles cite this article - sign up in the box at the Service top right corner of the article or click here.

To subscribe to RNA go to:

http://rnajournal.cshlp.org/subscriptions 